\title{
Enhancing Agro Climatic Information Systems (AGIS)-Led Response Farming under Climate Variability in Ethiopia
}

\author{
Abbadi Girmay Reda* \\ Tigray Agricultural Research Institute, Ethiopia \\ Submission: October 25, 2017; Published: October 27, 2017 \\ *Corresponding author: Abbadi Girmay Reda, Tigray Agricultural Research Institute, Mekelle, Ethiopia, Email: abbadigirmayreda@gmail.com
}

Abbreviations: SLM: Sustainable Land Management; CBIWSM: Community Based Integrated Watershed Management; TARI: Tigray Agricultural Research Institute

\section{Short Communication}

Agricultural productivity in Dryland areas of Ethiopia is poor due to low use of modern inputs, erratic rainfall and frequent droughts, soil fertility exhaustion, and land degradation. Measurements from experimental plots and micro-watersheds showed that the highest rate of soil loss occurs from cultivated fields, which is 42tonn/ha/year (Hurni, 1993). According to Sonneveld 2002 (cited by Bewuket, 2009), the cost of soil erosion to the national economy is about USD 1.0 billion per year. Lack of supportive polices and strategies further aggravated the problem. In Tigray Regional State, the natural resource bases of the region have been continuously exploited for a long period of time without appropriate conservation practices for sustainable use. These inappropriate use have led to cyclic drought, environmental degradation, decrease in productivity and deep rooted poverty.

Prominent challenges include: Land resources degradation, recurrent and cyclic drought and declining productivity. Land degradation is manifested in many ways in the region: Vegetation degradation (deforestation \& loss of species richness) habitat destruction, loss of biodiversity, enhanced soil erosion (declining soil fertility, low agricultural productivity), destruction of landscape/ ecology/ ecosystems deterioration of water resources and undesired climatic changes. Owing to these factors, the agricultural productivity and the overall production has continued to deteriorate. An option for adaptation to climate change and necessary condition for sustainable agriculture in itself is sustainable land management (SLM) and rehabilitation of degraded lands. Community Based Integrated Watershed Management (CBIWSM) approach was adopted as one of the top climate change adaptation strategies in Ethiopia. Massive sustainablelocal community based natural resource management efforts have been undertaken to reverse this situation and there are a lot of success stories in the last 25 years.

The pillars of the Ethiopian Growth and Transformation (GTPII: 2008-2012 EC) Plan includes: Food and nutrition security, agro processing, import substitution, enhancing foreign earnings, climate resilience green economy, and sustainable development and utilization of the natural resources bases. Addressing food and nutrition security, climate resilience, agricultural transformation, and industrialization requires investments, not only with capital but also in knowledge for smarter solutions. To this effect, Tigray Agricultural Research Institute (TARI) has been involved in adapting, generating and promoting agricultural technologies that enhance food security, supply inputs to agro-industries and generate foreign currency. These technologies have contributed to the growth of the region and improved livelihood of the farming community. Cognizant of the importance of agricultural technologies, TARI undertakes research in GTP-II period with the objective of adapting, generating and promoting agricultural technologies that enhance productivity and commercialization based on clustering, agro ecology, and value-chain approaches.

The agricultural sector of Tigray is inherently rain-fed, mainly characterized by small scale mixed farming system. The climate is mainly semi-arid characterized with small and erratic rainfall that varies both spatially and temporally. Moreover, the kiremt rainfall is inconsistent and unpredictable. This necessitates some form of coping mechanism both at community and government levels and regional scales. Because of the low and highly variable rainfall, both between and within seasons, agricultural productivity in the region will remain far below attainable and potential yields which could tremendously 
affect the livelihood of the farming community in the region. The impact of climate change in Tigray is significant and small scale farmers are and will be highly vulnerable. Therefore, to reduce the foreseeable impacts of climate change, farmers need to acquaint with a package of technologies that helps to adapt possible shocks.

It is also equally important that these technologies must be simple to practice and relevant to the knowledge and capacity of the farmers. This requires the involvement of different stakeholders that thrive improving the livelihood of small scale farmers. The Eastern escarpments of Ethiopia are the most degraded and drought prone regions in Ethiopia. Ethiopia is expected to be hardest hit by climate change and the most vulnerable sectors are agriculture, water resources and human health. It is predicted that climate change could lead to increased water stress and overall reduction in agricultural productivity. Climate change can significantly reverse the progress towards poverty reduction and food security in Ethiopia. Over the last five decades frequency of occurrence of extreme weather events such as drought and flood show an increasing trend.

Seasonal and inter-annual rainfall variability has increased and temperature shows an increasing trend. Analyzing and assessing the spatiotemporal climate variability trends would help better understand impacts of climate change to formulate better strategies for climate change adaptation and mitigation in Ethiopia and encourage local proactive community participation and national efforts as a contribution to global climate change mitigation. Analysis of seasonal rainfall averages against time indicates a significant decline trend. Temperature shows increasing trend but rainfall shows fluctuation. It is not the amount of rainfall but its unpredictable onset, cessation and intensity impacts on agriculture in Ethiopia. Action-research on agro climatologically. Early Warning Systems and technologies for enhanced land productivity to promote resilience at farm level through integration of decision support tools of agro climatology and resilient technologies of resource conservation, management, and agronomic practices will fill knowledge gaps for better results and will have policy and planning implications at local level in designing locally fit adaptation and mitigation strategies to minimize effects of climate variability for sustainability of livelihoods and natural resources in the face of climate change. This will enable farmers to adopt new technologies to sustain Dryland agriculture to endure shocks and improve their livelihoods.

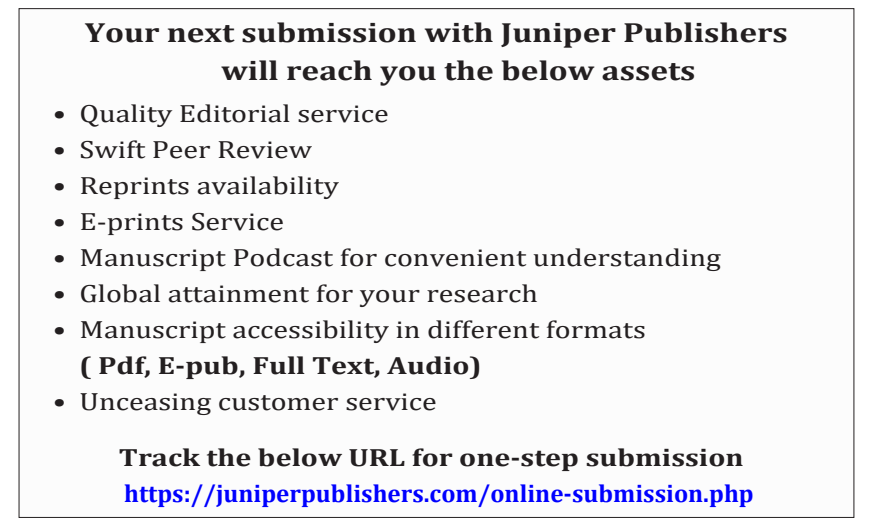

